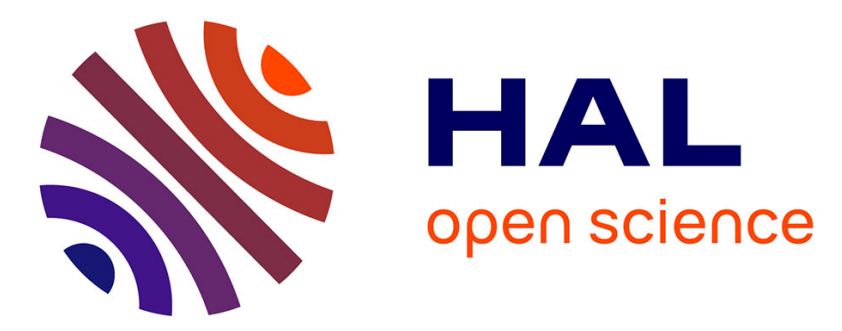

\title{
An attempt towards an integrative comparison of psychoanalytical and sensorimotor control theories of action
}

Ariane Bazan

\section{- To cite this version:}

Ariane Bazan. An attempt towards an integrative comparison of psychoanalytical and sensorimotor control theories of action. P. Haggard, Y. Rossetti \& M. Kawato (éds.),. Sensorimotor Foundations of Higher Cognition Attention and Performance XXII, New York: Oxford University Press, pp.319-338, 2007, 9780199231447. hal-03456358

\section{HAL Id: hal-03456358 \\ https://hal.science/hal-03456358}

Submitted on 29 Jan 2022

HAL is a multi-disciplinary open access archive for the deposit and dissemination of scientific research documents, whether they are published or not. The documents may come from teaching and research institutions in France or abroad, or from public or private research centers.
L'archive ouverte pluridisciplinaire HAL, est destinée au dépôt et à la diffusion de documents scientifiques de niveau recherche, publiés ou non, émanant des établissements d'enseignement et de recherche français ou étrangers, des laboratoires publics ou privés. 


\title{
An attempt towards an integrative comparison of psychoanalytical and sensorimotor control theories of action
}

Ariane Bazan, Research Unit on Neuro-Psychoanalysis, Department of Psychoanalysis and Consulting Psychology, University of Ghent and Psychiatric Centre Sint-Amandus, Beernem, Belgium arianebazan@hotmail.com

\begin{abstract}
In his 'Project for a scientific psychology' Freud (1895) distinguishes two fundamental modes of mental functioning: primary processes, which aim at releasing received activations by the shortest pathways possible and secondary processes, which aim at producing adequate actions in order to realise specific alterations in the external world. In the modern neurosciences of the last 30 years numerous studies also resulted in the converging conclusion that two visual pathways could be differentiated in the brain, a dorsal pathway hosting vision for action and a ventral pathway hosting vision for identification (e.g. Ungerleider and Mishkin 1982; Milner and Goodale 1995). In this paper these psychodynamic and sensorimotor models are compared. This analysis starts with the observation that Freud, who adhered to the school of physiology of von Helmholtz, used a concept, called 'indication of reality', to characterise the function of the secondary process. It is proposed that this concept parallels the modern notion of 'efference copy'. On the basis of this parallel it is then proposed that the secondary process is carried by the dorsal pathway which hosts a comparison mechanism involving the efference copies. In Freud's model secondary process functioning has an inhibiting effect on primary processes. For this and other reasons, parallels are then proposed between the primary process and ventral pathway functioning, which is constrained by interferences from
\end{abstract}


the dorsal pathway. In final, a brief case description of a psychotic patient is commented from both sensorimotor and psychodynamic perspective. 
Introduction

With the publication of his seminal work 'The interpretation of dreams' in 1900, Freud moves from a predominantly private address for his theoretical elaborations to his friend Wilhelm Fliess to a large public address. This can be seen as coinciding with the elaboration of a psychoanalytic theory as a discipline with its proper framework and instruments. His publications prior to the 'The interpretation of dreams' are therefore sometimes called 'preanalytic' writings, of which the two most important are 'On aphasia, a critical study' (short: 'On aphasia', 1891) and 'The project for a scientific psychology' (short: 'The project', 1895). 'The project' is actually a manuscript which was originally destined only for Fliess and was first published after Freud's death in 1950. While the preanalytic writings are explicitly grounded in the neurology of his time, from 1900 on Freud seemingly abandons this terminology and starts to use a framework specific to psychoanalysis. Some have therefore considered that Freud's preanalytic writings should be read as a metaphor and that psychoanalysis starts with the rejection or neglect of neurological models (see e.g. Van de Vijver and Geerardyn 2002). However, in particular in his metapsychological writings, Freud explicitly uses his 'preanalytic' models to develop his theory. In 'The unconscious' (1915), for example, he not only refers to his linguistic model of 'On aphasia' (1891), but he adds these pages as an appendix to the paper. For these reasons, it might also be defended that Freud has always worked with a physiological framework while writing his psychoanalytical oeuvre. The fact that Freud continuously worked with different frameworks, including a philosophical one, might be one of the reasons for his intellectual rigour, which now enables a productive dialogue between psychoanalysis and neurosciences (e.g. Panksepp 1999; Shevrin 2001; Solms 2004; Bazan and Van Bunder 2005). 
In his 'Project for a scientific psychology' Freud (1895) starts with a fundamental distinction between two modes of mental functioning, called primary and secondary processes. It is remarkable that in the modern neurosciences of the last 30 years numerous studies issuing from different domains (electrophysiology, neuropsychology, functional neuroimaging) also resulted in the converging conclusion that two visual pathways could be differentiated in the brain, a dorsal pathway hosting vision for action and a ventral pathway hosting vision for identification (e.g. Ungerleider and Mishkin 1982; Jeannerod 1994; Milner and Goodale 1995; Rossetti and Pisella 2002). It is important to understand that Freud wrote the 'Project' by inferring from his clinical experience with unlesioned patients the constraints to which the nervous system should be submitted. Modern neuroscientists, in contrast, have described their model on the basis of clinical findings almost exclusively originating from brain lesioned people. In this paper it will be my aim to underscore possible parallels between these different models. The interest of this comparison is predominantly of a heuristic kind that goes both ways. At the one hand, it might enlarge the physiological understanding of Freud's mental model. This might be a benefit for psychoanalysis e.g. because it might reintroduce an intellectual strictness in the use of a terminology and a theoretical framework by the fact that some of its concepts might reveal to be common to both fields and should therefore be used in agreement with these fields. At the other hand, it might also enlarge the psychological understanding of the neuroscientific models. The psychoanalytical clinic allows a unique perspective on the human mind. Indeed, this clinic, embedded in its elaborate theoretical framework, has yielded insights which enable to make sense of a broad range of seemingly unsensical human behaviours in patients with both everyday or more heavy psychopathology. In this sense, psychoanalysis may have a privileged status for informing neurophysiological models of the mind. 


\section{Freud's Model of 'The Project'}

\subsection{Primary and Secondary Processes}

\section{The Distinction between Inside and Outside}

Freud (1895) considers the nervous system as the inheritor of the ancient protoplasm, characterized by an irritable external surface interrupted by considerable stretches of nonirritable surface. Unspecified quantities are received at the level of the surface of the protoplasm. The primary function of this nervous system then is the discharge of received quantities of activation. An increase in energy threatens to destabilise the system and therefore has to be released as soon as possible. This is the principle of inertia. Since release is the priority, it follows that "among the paths of discharge those are preferred and retained which involve a cessation of the stimulus" (Freud 1895: 296); this is what Freud (1895: 296) calls the 'flight from the stimulus'. This simple principle also applies to a complex nervous system of interconnected neurons: "A [quantity] which breaks into a neurone from anywhere will proceed in the direction of the contact-barrier with the largest facilitation (...)." (Freud 1895: 323). Primary processes, then, are those mental processes that are characterized by these functional principles of releasing received activations by the shortest pathways possible.

When the protoplasm evolves into a structured living organism, closure implies that a fundamental distinction is settled between two kinds of stimuli received at the level of the irritable surface: namely, those stimuli that can be stopped by simple flight reactions and those that cannot be stopped by fleeing. In other words, as soon as a living organism arises, a difference between inside and outside is constructed (Maturana and Varela 1980). The endogenous stimuli have their origin in the cells of the body and give rise to the major needs, 
such as respiration, hunger, thirst, sexuality etc. Importantly, Freud (1895: 317-8) indicates: "The removal of the stimulus is only made possible by an intervention which calls for an alteration in the external world (supply of nourishment, proximity of the sexual object) which, as a specific action, can only be brought about in definite ways.”. Secondary processes, then, are those mental processes which bring about specific - or what Freud calls 'adequate' actions that aim at producing specific alterations in the external world. Because of the human's newborn child fundamental helplessness, most of the first adequate actions require the interaction with a fellow human being. When this fellow human helps the child, it will be "in a position, by means of reflex contrivances, immediately to carry out in the interior of his body the activity necessary for removing the endogenous stimulus.” (Freud 1895: 318). For example, if the mother upon hearing her baby crying, has brought the child's mouth to her breast or to a bottle, reflex sucking movements will be enough for relief of the hunger signals.

\section{The Emergence of an Organized Memory Structure}

A successful adequate act has major consequences for the organisation of the mental apparatus. First, it constitutes an experience of satisfaction, which has, according to Freud (1895: 318), three important consequences: (1) a lasting relief of the internal body tensions which had produced unpleasure; (2) an activation of the neurones which correspond to the perception of the object of satisfaction; and (3) feedback of the discharge of the released reflex movement which follows upon the specific action. In the case of the newborn drinking, there is a relief of the hunger excitation, an activation of a neuronal assembly corresponding to the perception of e.g. mother's breast and feedback of the sucking movement. Second, the experience of satisfaction reorganizes the neuronal pathways by facilitating the connection between these three neuronal events, i.e. between the activation indicating the internal tension or 'urgency' and the two memory images, namely the perceptual image of the object of 
satisfaction and the image of the satisfying movement (Freud 1895: 319). These facilitations are the basis for an emerging organisation in the mental apparatus during development, which gives rise to the 'ego' (Freud 1895: 323). The ego, then, is defined here as the total activation at a given time in a particular set of neurones which are also constantly excited by endogenous quantities and which have acquired an organisation through facilitation.

However, in some cases it might happen that endogenous excitations signalling a need induce a wishful state in the ego and activate the two memory images, while the object of satisfaction is not actually present (Freud, 1895: 319). When hunger arises in a baby, for example, this then will cause the baby to 'see' a breast or a bottle and to execute a sucking movement, even if there is no mother nor bottle present. The wishful activation thus produces the same thing as a perception, namely a hallucination. When reflex action, such as the sucking movement, is thereupon started, the baby will be disappointed. Moreover, it might also happen that a reactivation of a hostile memory image is about to lead to the massive release of unpleasure and of defence, while the image comes from the inner mental life and not from the outside. For example, a stimulus such as a large shadow might lead to the activation of a memory image of an intruder and to the consecutive release of a defence reaction, such as running away. It is clear that these reactions become problematic as soon as they become automatic or reflexive, i.e. as soon as the flow of excitations follows the most facilitated pathway and therefore functions at the level of the primary process.

In other words, the first facilitations, brought about by satisfaction, produce an initial structure of the ego, which helps to deal with endogenous activations, but does so, in first instance, on a primary process mode. The primary process way of acting, however, assumes an unchanged world: perceived features of the stimulus activate previous pathways independent of the new 
context. For the external stimulations in a simple organism, this might be a successful strategy since it is often enough to fly to get rid of them. The first response of the system to the internal stimuli is to follow the same pattern, i.e. to get rid of them by following the fastest paths already present in memory. But it then quickly becomes clear that this primary process mode does not always seem to work, especially for the internal stimulations. To the contrary, quite often these actions do not bring relief of the tensions and result in disappointment, frustration or even damage. These new experiences add to the previous and produce novel pathways which further help to elaborate the complexity of the ego.

\section{Structure Interferes with Primary Processes}

It is this increasing complexity then which will provide means to interfere with the primary processes. Indeed, as a consequence of the fact that many different associations, or scenarios, are possible starting by the same (endogenous) stimulus, the processing of the stimulus is slowed down or, as Freud says, inhibited. Here Freud (1895: 319) gives a mechanical account: "[An intracellular quantity] in neurone $\alpha$ will go not only in the direction of the barrier which is best facilitated, but also in the direction of the barrier which is [excited] from the further side.". The so-called 'side-cathexes' ('side-excitations'), or simultaneously active networks, are able to absorb the initial (endogenous) activations, and this is the mechanical

principle for the inhibitory action of the ego (see Figure 1). Stated in modern terms, in a mature or heavily connected network of neurones, the progression of an activation is spread over multiple cortical areas such that the activation in original automatic or short-track pathways gets dissolved or attenuated. It is this inhibition exerted by the ego which will make possible the use of a criterion for the discrimination between inner mental and external real world. 


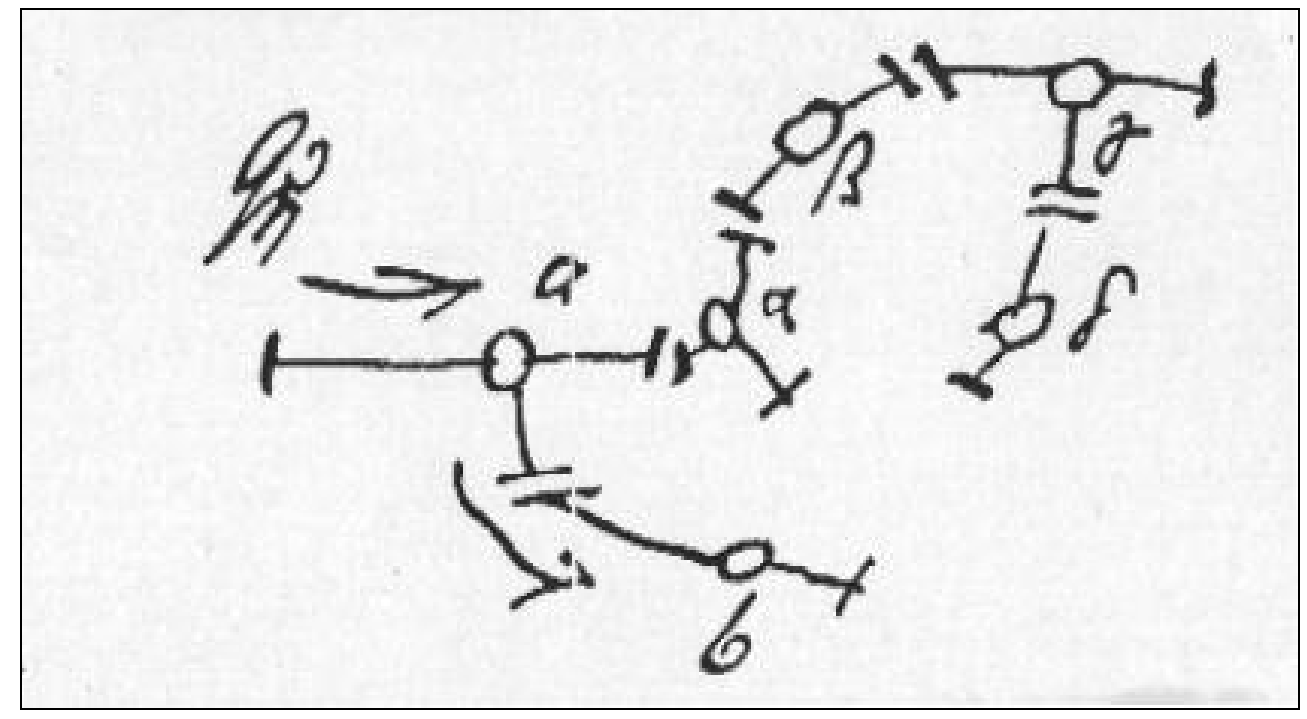

Figure 1: "Let us picture the ego as a network of cathected neurones well facilitated in relation to one another (...). If we suppose that [an intracellular quantity] Q $\eta$ enters a neurone $a$ from outside (...), then, if it were uninfluenced, it would pass to neurone $b$; but it is so much influenced by the side-cathexis [i.e. side-activation] $a-\alpha$ that it gives off only a quotient to $b$ and may even perhaps not reach $b$ at all. Therefore, if an ego exists, it must inhibit psychical primary processes." (Freud 1895: 324)

\section{Summary and Consequences}

A summary of the comparison between Freudian primary and secondary processes is proposed in Table 1.

Primary Process

\begin{tabular}{ccc}
\hline $\begin{array}{c}\text { Evolutionary } \\
\text { Pressure }\end{array}$ & $\begin{array}{c}\text { excitation of the external } \\
\text { surface of the protoplasm }\end{array}$ & $\begin{array}{c}\text { emergence of an inner body } \\
\text { in the organism }\end{array}$ \\
\hline Aim & $\begin{array}{c}\text { relief of received } \\
\text { (external) quantities }\end{array}$ & $\begin{array}{c}\text { relief of accumulating } \\
\text { (endogenous) activations }\end{array}$ \\
\hline Movement & reflex-type reaction & specific or adequate action \\
\hline Mechanism & flight from the stimulus & interference and inhibition \\
\hline Result & $\begin{array}{c}\text { inertia / } \\
\text { wishful hallucination or } \\
\text { massive defence }\end{array}$ & $\begin{array}{c}\text { experience of satisfaction / } \\
\text { experience of frustration }\end{array}$
\end{tabular}

Table 1: Comparison between primary and secondary processes according to Freud (1895). 
In a phylogenetic perspective, primary process dynamics respond to an evolutionary pressure to get rid of external stimuli, while secondary process dynamics have developed under pressure to handle inner body stimuli; in a logical perspective, however, the aim of both processes is not fundamentally different, namely, to get rid of activations. While in a more primitive environment simple flight reactions are often sufficient to stop external excitation, internal activation urges the organism to undertake specific actions upon its environment, which requires for a preliminary discrimination between between mental and real objects. In more complex environments, however, external stimulation often confront the organism with the same challenges as internal activations and require secondary process handling as well.

Freud indicates that primary and secondary processes are not parallel but hierarchically dependent processes: specifically, for secondary processes to take place, primary processes have to be inhibited, i.e. their access to full effective execution has to be prevented. This inhibition is brought about by the ego: it is its organisation with multiple elaborate networks that allows flexible interference with more linear primary processes. Interference here means that instructions for actions do not solely depend on the incoming information, but that this incoming information is cross-checked with an already established internal organised structure; resulting decisions for action will then depend on this process of integration of new information in the existing structure (see also Merleau-Ponty 1963). Importantly, this internal organised structure reflects the history of how the subject's endogenous needs encountered satisfaction (or lack thereof) in the interaction with objects and with others.

Stated differently, the primary process functions with the stimulus information as the only reference point: starting from the stimulus a causal chain, facilitated in memory, is activated 
which progresses linearly forward. In contrast, when the same stimulus is processed in a secondary process way, it is integrated in an already established organised structure, the ego, which is actualised on a moment-by-moment basis by the internal excitations signalling the current state of the body (e.g. hunger, thirst, temperature, fatigue, tensions etc.) and which enables to discriminate the source of the stimulus. In other words, while in the primary process there is no reference point for action besides the stimulus itself, the secondary process functions by relating the stimulus information to a reference point reflecting the current state of the body.

\subsection{Indications of reality}

As mentioned, for the secondary process to operate functionally, there must be a way to discriminate the origin of the activations in the wishful, respectively the hostile images. Indeed, in the case that these images are not originating from the actual real world, but have an internal origin, it is important to inhibit the primary process type reactions they elicit. Hence, for the secondary process to intervene, "it is a question of an indication to distinguish between a perception and a memory (idea)" (Freud 1895: 325). Freud (1895: 325) formulates the hypothesis that "it is probably the $\omega$ neurones which furnish these indications of reality". These $\omega$ neurones have a particular status: even though they are 'activated along with perception' and 'behave like organs of perception' (Freud 1895: 309), their discharge direction is efferent, i. e. in the direction of motility (Freud 1895: 311). The $\omega$ neurones are thus a system of motor neurones which are engaged in the constitution of perception. Indeed, as is discussed further, Freud adhered to the neuro-anatomical views a late nineteenth century physiology school, chief among whom was Hermann von Helmholtz. Von Helmholtz (1867; 
1878) made the proposal that the main contribution to the perception is the motor command itself, rather than the sensations elicited by its execution; perception is then constituted as the systematicity which arises in the interaction between given motor commands and received sensations. This sensorimotor approach can also be found in Freud's thinking when he proposes: "it must be assumed that the $\omega$ neurons are originally linked anatomically with the paths of conduction from the various sense organs and that they direct their discharges back to the motor apparatuses belonging to those same sense organs." (Freud 1895: 326). Moreover, Freud (1895: 325) indicates: "In the case of every external perception a qualitative excitation occurs in $\omega(\ldots)$ [this] $\omega$ excitation leads to $\omega$ discharge, and information of this, as of every discharge, reaches $\Psi . "$ where $\Psi$ is a system of cortical neurones with memory capacity responsible for psychical processes in general (Freud 1895: 300). Freud (1895: 325) adds: "The information of this discharge from $\omega$ is thus the indication of quality or of reality for $\Psi$.”. Since information of the $\omega$ discharges is only produced when there is active perception through the $\omega$ neurons, this information then furnishes a criterion to distinguish external perceptions from internal images.

There is, however, one exception according to Freud (1895): namely, indications of reality will also be produced for internal mental images when these are massively activated, i.e. activated without attenuation from the ego. In other words, in the case of massive activation, a memory image acquires the same status as a perception, i.e. it becomes a hallucination. Therefore, only if there is inhibition by the ego the indications of $\omega$ discharge become indications of reality for distinguishing between perception and memory (Freud 1895: 326).

The fundamental difference between primary and secondary processes thus is that thanks to an operational ego, automatic activations of memory images are attenuated in the secondary 
process; the signs of reality under these conditions are indications of the real external presence of the object and the released action becomes an adequate action. Freud (1895: 3267) summarizes: "Wishful cathexis to the point of hallucination [and] complete generation of unpleasure which involves a complete expenditure of defence are described by us as psychical primary processes; by contrast, those processes which are only made possible by a good cathexis of the ego, and which represent a moderation of the foregoing, are described as psychical secondary processes.”.

\section{Comparison with Modern Sensorimotor Theories of Action}

3.1. The indications of reality and the efference copy model.

According to modern central monitor or internal forward models (e.g. Frith, 1992; Wolpert, 1997; Blakemore, Wolpert and Frith, 1998), the sensory consequences of a self-produced movement can be accurately predicted on the basis of a copy of their original motor commands or efference copy. This model was first introduced by von Helmholtz in the $19^{\text {th }}$ century to explain the localisation of visual objects. To calculate the localisation of an object in reference to the head, the central nervous system has to take both the retinal location of the object and the gaze direction into account. Von Helmholtz' (1867) genial idea then was that the brain predicts this position of the gaze on the basis of a copy of the motor command sent to the eyes, i.e. on the basis of what is now called the efference copy. In the modern efference copy models (e.g. Blakemore et al., 1998), the predicted sensory feedback, calculated on the basis of the efference copy, is compared with the actual sensory feedback. This prediction can be used to attenuate the sensory effects of the movement and thereby to distinguish sensory 
events due to self-produced motion from the (unattenuated) sensory feedback caused by the environment, such as contact with objects.

At the time when Freud was writing his 'Project', he was greatly influenced by the physicalist physiology of von Helmholtz (1867). Von Helmholtz was is in fact the founder of the school of physiology in which Freud received his training - the so-called Helmholtz School of Physiology, involving Brücke, du Bois-Reymond, and others. In the earlier written monograph 'On Aphasia', Freud (1891: 73) still uses the term 'innervation feeling' which was commonly known at that time (by, among others, Helmholtz, James, Bain, Wundt, and Mach - see James, 1890) to indicate the 'feeling of discharge into the motor nerves' upon which von Helmholtz based his ‘efference copy’ model. Therefore, it appears through its writings that Freud was aware of von Helmholtz' model and adhered to it. In 'The Project' Freud (1895: 325) proposes that the 'indications of reality' are given by 'the informations of discharge', or, this is to say, literally from Freud's text, the 'Abfuhr Nachrichte', or 'efference messages'. Moreover, he specifies that these efference messages 'as for every efference message' flow back to the central nervous system (Freud 1895: 325). It is most likely, therefore, that Freud ${ }^{1}$ here uses von Helmholtz' model and, by extension, it does not seem a far stretch to suggest a parallel between the 'Abfuhr Nachricht' in Freud's model and the 'efference copy' in the recent forward models.

Importantly, the functions Freud assigns to the indications of reality bears similarities with those given to the efference. Indeed, the 'indications of reality' constitute the criterion which allows for the distinction between images generated upon external stimulation and those generated internally. When an image of an object is activated simultaneously with

\footnotetext{
${ }^{1}$ A probable reason why Freud does not explicitly refer to von Helmholtz here is that 'The Project' was a manuscript not destined for publication and published after his death in 1950 .
} 
information of active perception in (the $\omega$ neurones of) the visual apparatus, then there is reason to believe that the object is indeed present in reality, and action upon it can be released. In the modern forward models, the efference copy information constitutes a criterion to discriminate self from non-self. For example, efference copy information allows to recognize that a movement of the body is generated upon a self-generated command, and is not imposed upon the subject by an external intervention (Frith 1992). Because the sensory feedback of self-generated movements predicted on the basis of the efference copy is attenuated - a notion unknown in Freud's time - the forward model also allows to discriminate the sensory consequences of one's own movement and sensory input caused by the environment (e.g. Blakemore et al., 1998). In summary, there are historical, neuroanatomical and functional arguments for a parallel between Freud's indications of reality and modern efference copies.

3.2. The secondary process and the dorsal pathway.

If we accept this parallel, this has implications for Freud's model of primary and secondary processes. Freud (1895: 325) indicates that the secondary process can only operate if it can make use of the indications of reality. In other words, the secondary process can only be carried by a neuronal trajectory which implies the use of efference copies. Neuroanatomically, efference copies are generated at the level of the motor pathways from which they are derived, this is in the prefrontal cortex, especially the supplementary motor areas (Haggard and Whitford 2004). They are consecutively used in the control and the planning of action at the level of the dorsal trajectory over the parietal area (Blakemore and Sirigu 2003; Sirigu, Daprati, Ciancia, Giraux, Nighoghossian, Posada and Haggard 2004). Hence, for this and other reasons, which will be developed, a similarity between the secondary process and the dorsal pathway is proposed. 


\section{Intentional Action}

The dorsal pathway is the 'vision for action' pathway in Milner and Goodale's (1995) model. The dorsal stream and associated pathways are responsible for the programming and for the visual control of goal-directed action. The dorsal stream also corresponds to the 'pragmatic' processing in Jeannerod's (1994) and in Jeannerod and Jacob's (2005) revised look at the two-visual systems model; the pragmatic processing allows the handling of complex representations of actions such as schemas for the use of cultural tools. This function of the dorsal pathway corresponds with the function of the secondary process in Freud's model. The secondary processes, indeed, carry the deployment of 'specific' or 'adequate' actions; these adequate actions are called as such because they aim at producing a specific change in the external world which will adequately relieve a specific body tension. In other words, they are subject-centered actions which involve planning in function of an overarching subjective intention or goal.

\section{Spatial Localisation}

The dorsal pathway is also the pathway enabling spatial localisation. In Ungerleider and Mishkin's (1982) model the dorsal stream is the 'space channel' for object-discrimination on the basis of their location in space. In Milner and Goodale's (1995) model it is the pathway for visuomotor transformation, i.e. the automatic conversion of visual information of hand commands for reaching and grasping objects. Central to the dorsal pathway is the parietal cortex which plays an important role in assessing the context in which movements take place. To this end, the parietal cortex receives somatosensory, proprioceptive, auditory and visual information and uses this to determine the position of the body and the target in space (Andersen, Snyder, Bradley and Xing 1997). Efference copies of motor commands also 
converge on the posterior parietal cortex and provide information about body movements. All these signals are combined in the posterior parietal cortex to form a representation of space. This representation can then be used to construct frames of reference for the coding of appropriate movements (e.g. Jeannerod, Arbib, Rizzolatti and Sakata 1995).

Freud did not attribute to the secondary pathway the same spatial abilities as are described here for the dorsal pathway. However, his model should be read in the context of the physiological knowledge of his time. One of Freud's main distinctions between primary and secondary process is that the reaction carried by the primary process is a linear response - as a sort of mirror image - to the stimulus, while in the secondary process the ego interferes as a third point between the stimulus and the reactive tendency. This ego is defined as an activation in a set of neurones which is continuously updated by endogenous body information. These internal body stimulations (e.g. hunger) are not altered by moving the body (e.g. by fleeing) and can therefore actualise the function of the ego as a reference point independent from the stimulus. A simple illustration of this would be that a primary process reaction upon an image of a food item would be to initiate salivation, while a secondary process action would be to check the visual information for its locus of origin ('is it a mental or a real image?') and with the intentions of the organism given by the status of the inner body ('do I wish to eat it?') in function of the development of an action plan (e.g. to grasp the item). At this general level of spatiality, Freud's secondary process, as in contrast to his primary process, bears some similarities with the dorsal pathway. 
3.3. The primary process and the ventral pathway.

The ventral pathway is the 'object-channel' in Ungerleider and Mishkin's (1982) model, the perception pathway in Milner and Goodale's (1995) model or the pathway for the visual imagery of objects in Jeannerod and Jacob's (2005) model. The ventral stream extends from the striate cortex to the inferotemporal cortex and plays a major role in object recognition and identification: elementary visual percepts arise from the automatic stage of processing whereby basic visual attributes - such as contours, shape, texture, colour etc. - of an object are assembled and bound together. In the ventral stream the items of the visual scene are classified on the basis of representations stored in memory in the temporal lobe (Owen, Milner, Petrides and Evans 1996; Ishai, Ungerleider, Martin, Schouten and Haxby 1999). It is proposed that this ventral pathway, though at first sight quite different from the description of Freud's primary process, nevertheless bears remarkable points of similarity with it for reasons which will be developed.

\section{Object-centered Activation}

Primary processes are characterised by the type of treatment they carry, namely reflex-type re-actions, which are qualified in function of their eliciting stimuli: i.e. their form can be more or less linearly derived from the form of the incoming stimuli. Freud $(1895: 319,320)$ indicates that the primary process reacts in an immediate way on the perception of the stimulus which triggers the automatic activation of associated memory contents such as memory images of objects and actions. In other words, the primary process searches to establish an 'identity of perception' (Freud 1900: 671) between the incoming stimulus and the stored representations by the shortest pathway possible, be it in a hallucinatory mode. This 'identity of perception' is achieved by the fact that the primary process will lead to the 
activation of the same content elements independently of the context of the stimulus. In these aspects the primary process bears similarities with the ventral pathway, which is oriented on the immediate physical aspects of the stimulus (Freedman, Riesenhuber, Poggio and Miller 2003) and which is engaged in the identification of the stimulus independently of its spatial orientation (Milner and Goodale 1995) with the help of stored memory contents for objects or gestures (Owen et al. 1996; Ishai et al. 1999; Peigneux, Van der Linden, Garraux, Laureys, Degueldre, Aerts, Del Flore, Moonen, Luxen and Salmon, 2004).

The ventral pathway also corresponds to the pathway with 'actions with objects as goals' in Jeannerod's (1994) and the semantic pathway and Jeannerod and Jacob's (2005) model. These authors (Jeannerod and Jacob 2005: 303) describe this pathway as follows: "the goal of semantic processing of visual inputs is the recognition of objects which involves segregation of a scene into separable objects and binding to each objects of its appropriate visual attributes". This quote resonates with clinical descriptions of primary process dynamics in e.g. free association or dreaming. Indeed, these involve the segregation of a scene into separable objects and the treatment of the isolated objects regardless of their mutual relationships (Freud, 1900). Clinical observations and empirical results (e.g. Brakel, Shevrin and Villa 2002) also indicate that the primary process involves a parsing of the stimulus in its features, whereupon each feature is the starting point for an associative chain. This leads to a profusion of memory contents associated with the stimulus, which is what Freud (1895: 338) calls the 'compulsion to associate'. Here, then, there seems to be some agreement between the ventral pathway and the primary process at the level of its psychological manifestation. 


\section{Inhibition and Hierarchy}

Classically, the ventral pathway is considered the vision pathway for the conscious identification of objects, while the dorsal pathway is the vision-for-action pathway, engaging in a large number of operations which are not necessarily conscious (Milner \& Goodale 1995). This dichotomy has been questioned (e.g. Jeannerod 1999). For example, it appears that the ventral pathway can engage in an extremely rapid and largely automatised analysis of visual information (Thorpe and Fabre-Thorpe 2001). Moreover, the ventral pathway is able to perform parallel complex analyses on several objects simultaneously during a small time window; subsequently only one or a very few objects are explicitly selected and consciously perceived (Rousselet, Thorpe \& Fabre-Thorpe, 2004). The ventral pathway is integrated in a network of cortical areas allowing goal-oriented behaviours. Both the prefrontal cortex and the parietal cortex are thought to provide high-level, top-down constraints on computations performed in the ventral pathway (Desimone and Duncan 1995). The intervention of the parietal cortex, in particular, is needed to filter out the influence of distractors during object discrimination; areas V4 and the temporo-occipital cortex in the ventral pathway might receive top-down bias from parietal cortex, allowing a target to be explicitly reported (Friedman-Hill, Robertson, Desimone and Ungerleider 2003). The complex interactions between the different levels of the ventral pathway and the parietal cortex might therefore constrain the number of objects that can be perceived simultaneously and consciously reported (Rousselet et al. 2004). Similar conclusions might apply to the prefrontal cortex. For instance, a recent model has been suggested in which 'selection for action' in the frontal eye fields affects object representations in the ventral pathway (Hamker 2003). Overall, mechanisms in the prefrontal and parietal cortices constrain computations in the ventral pathway. 
These observations indicate a hierarchical relationship involving a constraining interference of the dorsal pathway and the prefrontal cortex on the ventral pathway. A hierarchical relationship of this kind at the behavioural level has also been shown. Glover (2004: 4), for example, states that "an integration of spatial characteristics with information about an object's identity is usually required to compute a nonspatial characteristic. However, the reverse is not also true: nonspatial characteristics are not required to compute spatial characteristics.". In Jeannerod and Jacob's (2005: 309) account, too, the level of awareness of the object's attributes depends on its spatial positioning: "Loss of awareness of the spatial relations between objects (provoked by a lesion in the right inferior parietal lobe) produces loss of awareness of other visual attributes.". This, however, they argue, is not true the other way around. Indeed, clinical observations with lesion patients show that "Loss of awareness of such visual properties of objects as their colour, shapes, sizes or orientations does not seem to lead to unawareness of the relative locations of objects." (Jeannerod and Jacob 2005: 309).

These hierarchical considerations are similar to the hierarchical approach of the secondaryprimary dichotomy. For the sensorimotor model, data suggest both a prefrontal and a parietal inhibitory effect on the ventral pathway. In Freud's model, the deployment of secondary processes involves the inhibition of primary processes; Freud mentions both a inhibitory influence of the ego (1895: 324) as well as a moderation effect of the secondary process (1895: 327; 1900: 603) on the primary process. It is interesting that there seems to be a parallel in function here between the ego and the prefrontal cortex; such a possible equivalence between the Freudian ego and the (pre-) frontal cortex has been proposed before (e.g. Kaplan-Solms and Solms 2000; Solms 2004). These similarities in interaction and inhibition dynamics between both models, psychodynamic and sensorimotor, strengthen the 
parallel between the secondary process and the dorsal pathway and between the primary process and the ventral pathway respectively.

\section{Conscious and Unconscious Processes}

The proposed parallels might sound surprising given the classical view, in which the ventral pathway is the pathway for conscious identification, while the dorsal pathway is the action pathway, which does not necessarily operate consciously (Milner \& Goodale 1995). This seems to be a contradiction with the psychodynamic topology, in which the primary processes are characteristic for unconscious mental life - as become manifest in e.g. free association, dreams, slips of the tongues, hysterical symptoms and schizophrenia - while secondary processing is characteristic for conscious mentation. Both models, however, need to be articulated more precisely in this respect.

First, as indicated, the sensorimotor model should be nuanced: indeed, it appears that not all ventral processing is conscious; moreover the selection of those ventrally processed contents which come to consciousness is likely operated by the dorsal pathway and the prefrontal cortex. In this understanding of the sensorimotor dichotomy, the dynamical interactions between ventral and dorsal pathways are quite similar to the interactions described by Freud. Indeed, primary processes are, in Freud's understanding, continuously operational, even when they are overridden by secondary processes: the interference of the secondary process is limited to the extent to which these primary processes have access to consciousness. When secondary processing is temporarily suspended, such as in dreams or in parapraxes, the primary process has an unrestrained access to consciousness. In conscious mental life this is mostly not the case, but even then, secondary processes are not to be equated with conscious 
experience itself. Instead, secondary processes enable mental operations which are typical for conscious mental life, such as the discrimination between mental and real images. These mental operations as such do not constitute the content of consciousness; instead, this content is given by those images that have not been prevented from access to consciousness by the ego. Moreover, once they have gone through this selection, the images - mental or real - are experienced together with an awareness of their origin, namely interior or exterior. This view is in agreement with Shevrin (1998), who proposes that the very function of consciousness for the mental apparatus is to enable the distinction of various mental contents in function of their origin, either external or internal, either percepts, memories thought or fantasies.

In the sensorimotor approach for access to consciousness, Jeannerod and Jacob (2005) stress the primacy of spatial localization. Based on clinical observations with brain lesioned patients, they contend that "visual processing in the dorsal pathway can build visual representations of the spatial relations among distinct proto-objects almost devoid of other visual attributes" (Jeannerod and Jacob 2005: 309). On the other hand, Jeannerod and Jacob (2005: 309) remark that "in neglect patients, the visual attributes of objects in the neglected hemispace are still covertly processed by the relevant areas in the ventral pathway. But the patient remains unaware of the visual attributes of stimuli located in their neglected hemispace.”. In other words, the authors defend the idea that spatial access is a condition for access to conscious mental contents, but the absence of it would not prevent unconscious processing of these contents; on the other hand, an absence of processing in the ventral pathway does not prevent a form of schematic consciousness. There is some correspondence between this view and Freud's model, since it stresses the role of the spatial localisation as an enabling condition for access to consciousness, the contents of which is then (also) given by 
the ventral pathway: in Freud's model, secondary processing is an enabling condition for access to consciousness while primary processing contributes to its contents.

If we do the hypothetical exercise of putting both models together, they seem to indicate that the enabling condition for consciousness of content - i.e. the access to what something is - is the primacy of establishing first that something is there which needs to be identified. This awareness of the fact that 'something is there' would be carried by the dorsal pathway in the sensorimotor model, because this is the pathway for spatial localisation. Parallelly, it would be carried by the secondary processing in the psychodynamic model, because this is the pathway that allows to establish the exteriority of a stimulus, i.e. the fact that something is there which is not me. Once this position or status of the stimulus is established, it can be given a contents, either by the ventral pathway in the sensorimotor model or by the primary processing in the psychodynamic model. Moreover, it is most probably the prior localisation of the stimulus which will constrain the selection of one identity amidst a range of possible identities. For the sensorimotor models, this is suggested by empirical results showing the selection effect of the dorsal pathway and the prefrontal cortex on the parallel processing in the ventral pathway (see 3.3.). For the psychodynamic models, this is suggested by clinical observations, showing a profusion of possible interpretations of a same stimulus - including a great many that make no sense in the given context - in situations of (temporary) suspension of secondary processing, such as in free association or in dreaming.

This line of thought has the advantage of explaining paradigms used to establish unconscious processing. Subliminal priming paradigms establish unconscious processing on the basis of the so-called 'dissociation paradigm': though people are completely unable to detect stimuli in a subliminal forced choice paradigm, they appear to perform significantly above chance on 
identification and categorization tasks presented at the same level of subliminality

(Snodgrass, Bernat and Shevrin 2004). This could be explained by the difference in status of detection at the one hand and identification or categorization at the other. Detection, indeed, by definition requires the ability to indicate that a mental content is coming from the outside world - and is therefore not merely a thought or a memory. For this reason, detection requires the ability to distinguish inside from outside, which is an ability of the secondary process. Identification and categorization tasks, in contrast, can be performed independently of the localization of mental contents. It does not matter if the stimuli are mental or real, as long as there is some access to the content of these stimuli, the identification and categorization tasks will not be performed randomly. Therefore, these task do not appeal to secondary processing but need only primary processing. If we venture to make a projection to the sensorimotor models along the lines of the paper, we would say that these tasks only require mobilization of the ventral 'What?' pathway, without need for information of the dorsal 'Where?' pathways.

\section{Clinical Illustration}

In the Freudian model, positive psychotic symptoms, such as hallucinations and perceptual distortions, are due to a relative supremacy of primary processes versus a downplay of secondary processes (1900: 568; 1915: 197, 199-204). Clinical observations of these psychotic experiences therefore inform us about what 'goes wrong' when there is a relative absence of secondary processing. This brief case description ${ }^{2}$ is from a patient with an

\footnotetext{
${ }^{2}$ Observations made by the author at the Psychiatric Centre Sint-Amandus in Beernem, Belgium, during the period September 2005 - February 2006 (see also Van de Vijver Bazan Rottiers Gilbert 2006).
} 
established DSM diagnosis of schizophrenia. The patient has a delusional system, reports voices and produces neologisms. He takes neuroleptic medication.

\section{Brief Description}

$\mathrm{RV}$ is a 45 years old man, whose major difficulty is that, often, when he directs a glance to the world, the perception of this world invades him. He complains of penetrating sensations, 'people and things sticking onto his skin', 'people walking through him', things 'penetrating him'. In other words, he has great difficulty to create an experience of distance between him and his percepts. To restore a bearable relation to the world, he has to physically move back and forth around his visual targets: he frequently backs up on his steps, to move forward again; he opens doors by opening them partially, then closing them again partially, then reopening them, etc.; he does and undoes repeatedly, either completely or partially, some of his gestures, both in the forward and in the backward direction. Specifically, he details one chain of events which is painful to him: moving people or things in the world cause a 'fizz' or a 'pinching feeling' on his retina, which then constitutes the unique cause of an 'undesirable image'. These undesirable images are often of an incisive and penetrating content, such as: 'a needle in the eye', 'the disintegration of my photo-apparatus', 'a penis through my knife', 'my pectoral muscle torn', 'my viscera extirpated', 'my balls unhooked' etc. To undo the image, the moving target that caused the pinch on his retina is asked to undo the movement: he asks people around him to back up, to undo in backward direction what they did in the first place. When they accept to do so, he watches the scene fixedly, leans his head somewhat forward, firmly closes his eye and holds this pose for a second, before looking up again. In case they do not accept to submit to his request, he remains pursued by the painful image. Places where he has been are thus occupied with an accumulation of as yet undone undesirable images. 


\section{Comments}

Since in a psychodynamic perspective the secondary processing is thought to be relatively absent in psychosis, one hypothesis might be that the indications of reality corresponding with RV's visual perception are lacking or disturbed. Since the indications of reality have the function to distinguish interior from exterior or 'me' from 'not-me', the expected consequence of this disturbance would then be a difficulty in experiencing the exteriority of the visual percepts, which is exactly what RV complains about. If we apply to this case the proposed parallel between the indications of reality and the efference copies (see 3.1.), the hypothesis would be that RV's disturbance is situated at the level of the efference copies of his eye movements.

If this is true, a number of consequences are expected. First, the reflexive eye movement following a moving target would still occur, but would not be recognized as being under command of the self. In other words, it would feel as if the eyes were forced by some external agent to make small movements to follow the target, something one could tentatively describe as a 'pinching' on the retina, which is what RV reports about his experience. The supposedly missing efference copies would coincide with Frith's hypothesis (1992) for the voices heard by psychotic patients: these are thought to be due to self-generated subvocal movements of the articulatory system which are not recognized as being self-generated, for reason of a possible missing of the efference copies. In Blakemore et al.'s (1998) comparator model, the efference copies enable the anticipation of the sensory feedback of the activated movement such that this sensory feedback is pre-emptively attenuated. If the efference copies of the eye movements are supposedly missing or disturbed in RV, then the consecutive attenuation should also be lacking, which might explain RV's conscious experience of his eye movement 
upon a moving target. Second, in a sensorimotor approach of normal perception (e.g. Glover 2004: 6-7) the combined visual and proprioceptive feedback and efference copy information are fed to the dorsal pathway over the superior parietal lobe, which is responsible for establishing the spatial object properties model. If a disturbance at the level of the efference copies of the eye-movements is supposed, it makes sense that this would manifest itself at the level of the spatial experience of the percepts.

Moreover, in an enactive perspective (e.g. Noë 2005), a perception is constituted by the implicit knowledge of the sensorimotor contingencies decribing the way sensory stimulation varies with movement. Lenay $(2006: 39 ; 41 ; 43)$ proposes that the ability to create an experience of distance or an exterior space for the content of what is perceived, is precisely the ability to reversibly move back and forth around the visual target. This movement would normally be constituted by a structurally unconscious eye-movement around the target. The idea that RV's inability to create an impression of distance correlates with the impression that his eye-movements are at that moment not unconscious or not attenuated, might suggest that this attenuation is a necessary condition for the creation of an exterior perception space and of the experience of distance. In any case, if we suppose that RV's eye movements are at particular moments not able to create this experience of distance, he might be tempted to replace this back-and-forth eye movement by a back-and-forth body movement, which is what is observed. The hypothesis of a disturbance at the level of the efference copies of RV's eye movements therefore allows to explain some of his observed behaviours.

Finally, one probably wonders how to understand RV's profusion of undesirable images in this context. In a Freudian approach this could be understood as the consequence of the relative absence of the secondary processing: in an attempt to make sense of the experience of 
intrusion, RV produces in an associative way an unrestrained range of primary process (memory and fantasy) contents which then have a relative easy access to consciousness. If the secondary processes would be functional, they would verify that these images do not correspond with reality and refrain their access to consciousness; without the selective influence of the secondary process, a direct 'window into RV's unconscious' opens up.

In summary, the analysis of this brief clinical description is coherent with the Freudian hypothesis of a downplay of the secondary processes and a problem at the level of the 'indications of reality'. In parallel, a sensorimotor disturbance in the dorsal pathway with a problem at the level of the efference copies would also coherently make sense of the observed symptoms. Several studies have indeed indicated a disturbance of the dorsal parietal pathway (e.g. O'Donnell, Swearer, Smith, Nestor and Shenton, McCarley 1996; Doniger, Foxe, Murray, Higgins and Javitt 2002; Maruff, Wilson and Currie 2003; Kim, Wylie, Pasternak, Butler and Javitt 2006; Danckert, Rossetti, d'Amato, Daléry and Saoud 2002) in the pathophysiology of schizophrenia. These clinical observations, then, give further support to the suggestion of a similarity between the secondary process and the dorsal pathway.

\section{Conclusions}

To conclude this comparison between a psychodynamic concept of the mental apparatus and a sensorimotor brain concept, it is proposed (1) that Freud's concept of indications of reality parallels the modern concept of efference copies and (2) that the neurophysiological ventral-dorsal dichotomy allows a dissociation of mental processing compatible with the Freudian primary-secondary dichotomy. On this basis, the primary process is argued to 
involve the ventral pathway, and the secondary process to involve the dorsal pathway. The specific points of similarity between the Freudian and the sensorimotor model are summarized in Table 2.

Model

Freud

\begin{tabular}{|c|c|c|}
\hline & Primary process & Ventral pathway \\
\hline Reacts & $\begin{array}{l}\text { in an immediate way on the } \\
\text { features of the stimulus }\end{array}$ & $\begin{array}{l}\text { in an immediate way on the } \\
\text { features of the stimulus }\end{array}$ \\
\hline Aims at & 'perceptual identity' & recognition and identification \\
\hline Is insensitive to & $\begin{array}{l}\text { contextual configuration of the } \\
\text { stimulus }\end{array}$ & $\begin{array}{c}\text { spatial configuration of the } \\
\text { stimulus }\end{array}$ \\
\hline Is characterised by & $\begin{array}{l}\text { a profusion of associated } \\
\text { memory contents }\end{array}$ & parallel processing \\
\hline Is inhibited by & the ego & prefrontal fibres \\
\hline \multirow[t]{2}{*}{ Delivers after selection } & contents of consciousness & contents of consciousness \\
\hline & Secondary process & Dorsal pathway \\
\hline Makes use of & indications of reality & efference copies \\
\hline Aims at & specific or adequate actions & $\begin{array}{l}\text { goal-directed, planned or } \\
\text { intentional actions }\end{array}$ \\
\hline $\begin{array}{l}\text { Is able to take the locus } \\
\text { of the stimulus into } \\
\text { account thanks to }\end{array}$ & $\begin{array}{l}\text { a reference point independent } \\
\text { of the stimulus given by the } \\
\text { unfleeable internal activations }\end{array}$ & spatial localisation \\
\hline Constrains & primary processes & ventral pathway \\
\hline Enables & access to consciousness & access to consciousness \\
\hline
\end{tabular}

Table 2: Comparison between the Freudian model of the mental apparatus (1895) and modern sensorimotor two-visual systems models. 


\section{ACKNOWLEDGMENTS}

The author thanks Gertrudis Van de Vijver and Yves Rossetti for critical comments and discussion. Support for this research was provided by Howard Shevrin, the Belgian American Educational Foundation and the International Neuro-Psychoanalysis Society. 


\section{REFERENCES}

Andersen RA, Snyder LH, Bradley DC and Xing J (1997). Multimodal representation of space in the posterior parietal cortex and its use in planning movements. Annual Review of Neuroscience, 20, 303-30.

Bazan A and Van Bunder D (2005) Some comments on the emotional and motor dynamics of language embodiment. A neurophysiological understanding of the Freudian Unconscious. In: H De Preester and V Knockaert, eds. Body Image \& Body Schema, interdisciplinary perspectives, pp. 49-107. John Benjamins, Amsterdam/Philadelphia.

Blakemore SJ and A Sirigu (2003). Action prediction in the cerebellum and in the parietal lobe. Experimental Brain Research, 153, 239-45.

Blakemore SJ, Wolpert DM and Frith CD (1998). Central cancellation of self-produced tickle sensation. Nature Neuroscience, 1, 635-40.

Brakel LAW, Shevrin H and Villa KK (2002). The priority of primary process categorizing: experimental evidence supporting a psychoanalytic developmental hypothesis. The Journal of the American Psychoanalytic Association, 50 (2), 483-505.

Danckert J, Rossetti Y, d'Amato T, Daléry J and Saoud M (2002). Exploring imagined movements in patients with schizophrenia. NeuroReport, 13, 605-9.

Desimone R and Duncan J (1995). Neural mechanisms of selective visual attention. Annual Review of Neuroscience, 18, 193-222.

Doniger GM, Foxe JJ, Murray MM, Higgins BA and Javitt DC (2002). Impaired visual object recognition and dorsal/ventral stream interaction in schizophrenia. Archives of General Psychiatry, 59, 1011-20.

Freedman DJ, Riesenhuber M, Poggio T and Miller EK (2003). A Comparison of Primate Prefrontal and Inferior Temporal Cortices during Visual Categorization. Journal of Neuroscience, 23, 5235-46. 
Freud S (1891/1978). On aphasia, a critical study. (E Stengel, translator). International Universities Press, New York.

Freud S (1895/1966). Project for a scientific psychology (J Stratchey, translator). In Standard Edition I, pp. 281-397/410. The Hogarth Press, London. (Original publication in 1950). Freud S (1900/1958). The Interpretation of Dreams (J Stratchey, translator). In Standard Edition $I V-V$, pp. 339-627. The Hogarth Press, London.

Freud S (1915/1957). The Unconscious (J Stratchey, translator). In Standard Edition XIV, pp. 159-215. The Hogarth Press, London.

Friedman-Hill SR, Robertson LC, Desimone R and Ungerleider LG (2003). Posterior parietal cortex and the filtering of distractors. Proceedings of the National. Academy of Sciences of the USA, 7, 4263-8.

Frith CD (1992). The neuropsychology of schizophrenia. Lawrence Erlbaum, Hove.

Glover S (2004). Separate visual representations in the planning and control of action. Behavioral and Brain Sciences, 27, 3-78.

Haggard P and Whitford B (2004). Supplementary motor area provides an efferent signal for sensory suppression. Cognitive Brain Research, 19, 52-8.

Hamker FH (2003). The reentry hypothesis: linking eye movements to visual perception. Journal of Vision, 3, 808-16.

Helmholtz H von (1867/1962). Handbuch der physiologischen Optik. Leopold Voss. $12^{\text {th }}$ Edition, Hamburg. [English translation: JPC Southall, ed. and trans. (1962) A Treatise on Physiological Optics. Dover, New York.].

Helmholtz H von (1878/1971) The Facts of Perception. In Kahl R, ed. Selected Writings of Hermann von Helmholtz. Wesleyan University Press, Middletown, CT. 
Ishai A, Ungerleider LG, Martin A, Schouten JL and Haxby JV (1999). Distributed representation of objects in the human ventral visual pathway. Proceedings of the National. Academy of Sciences of the USA, 96, 9379-84.

James W (1890/1981). The Principles of Psychology. Dover, New York.

Jeannerod M (1994). The representing brain: Neural correlates of motor intention and imagery. Behavioral and Brain Sciences, 17, 187-245.

Jeannerod M, Arbib MA, Rizzolatti G and Sakata H (1995). Grasping objects: the cortical mechanisms of visuomotor transformation. Trends in Neurosciences, 18, 314-20.

Jeannerod M and Jacob P (2005). Visual cognition: a new look at the two-visual systems model. Neuropsychologia, 43, 301-12.

Kaplan-Solms K and Solms M (2000). Clinical Studies in Neuro-Psychoanalysis. Introduction to a Depth Neuropsychology. International Universities Press, Madison, Connecticut.

Kim D, Wylie G, Pasternak R, Butler PD and Javitt DC (2006). Magnocellular contributions to impaired motion processing in schizophrenia. Schizophrenia Research, 82, 1-8 Lenay C (2006). Enaction, externalisme et suppléance perceptive. Intellectica, 43, 27-52. Maruff P, Wilson P, Currie J. (2003). Abnormalities of motor imagery associated with somatic passivity phenomena in schizophrenia. Schizophrenia Research, 60, 229-38. Maturana HR and Varela FJ (1980). Autopoiesis and Cognition: The Realization of the Living. Boston Studies in the Philosophy of Science, 42. D. Reidel, Dordrecht.

Merleau-Ponty M (1963/1983). The structure of behaviour. Duquesne University Press, Pittsburgh.

Milner AD and Goodale MA (1995). The visual brain in action. Oxford University Press, Oxford.

Noë A (2005). Action in Perception. MIT Press, Cambridge, MA. 
O'Donnell BF, Swearer JM, Smith LT, Nestor PG, Shenton ME and McCarley RW (1996).

Selective deficits in visual perception and recognition in schizophrenia. American Journal of Psychiatry, 153, 687-92.

Owen AM, Milner B, Petrides M and Evans AC (1996). Memory for object features versus memory for object location: A positron-emission tomography study of encoding and retrieval processes Proceedings of the National. Academy of Sciences of the USA, 93, 9212-7.

Panksepp J (1999). Emotions as viewed by psychoanalysis and neuroscience: An exercise in consilience. NeuroPsychoanalysis, 1,15-38.

Peigneux P, Van der Linden M, Garraux G, Laureys S, Degueldre C, Aerts J, Del Flore G, Moonen G, Luxen A and Salmon E (2004). Imaging a cognitive model of apraxia: the neural substrate of gesture-specific cognitive processes. Human Brain Mapping, 21, 11942.

Rossetti Y, Pisella L (2002). Several 'vision for action' systems: a guide to dissociating and integrating dorsal and ventral functions. In W Prinz, B Hommel, eds. Common Mechanisms in Perception and Action, Attention and Performance, volume XIX, pp. 62119, Oxford University Press, Oxford.

Rousselet GA, Thorpe SJ and Fabre-Thorpe M (2004). How parallel is visual processing in the ventral pathway? TRENDS in Cognitive Sciences, 8, 363-70.

Shevrin H (1998). Why do we need to be conscious? A psychoanalytic answer. In DF Barone, M Hersen and VB VanHasselt, eds. Advanced Personality, Chapter 10. Plenum Press, New York.

Shevrin H (2001). Event-related markers of unconscious processes. International Journal of Psychophysiology, 42, 209-18. 
Sirigu A, Daprati E, Ciancia S, Giraux P, Nighoghossian N, Posada A and Haggard P. (2004). Altered awareness of voluntary action after damage to the parietal cortex. Nature Neuroscience, 7, 80-4.

Snodgrass M, Bernat E and Shevrin H (2004). Unconscious perception: a model-based approach to method and evidence. Perception \& Psychophysics, 66, 846-67.

Solms M. (2004). Freud returns. Scientific American, 290, 83-8.

Thorpe SJ and Fabre-Thorpe M (2001). Seeking categories in the brain. Science, 291, 260-3.

Ungerleider L and Mishkin M (1982). Two cortical visual systems. In DJ Ingle, MA Goodale and RJW Mansfiled, eds. Analysis of visual behaviour, pp. 549-86. MIT Press, Cambridge.

Van de Vijver G and Geerardyn F (2002). The pre-psychoanalytic writings of Sigmund Freud. Karnac, London.

Van de Vijver G, Bazan A, Rottiers F and Gilbert J (2006). Enactivisme et internalisme: de l'ontologie à la clinique. Intellectica, 43, 93-103.

Wolpert DM (1997). Computational approaches to motor control. Trends in Cognitive Sciences, 1, 209-16. 